\title{
Kurt Simon wird 80 Jahre
}

Herr Professor Dr. med. Kurt Simon war von 1953 bis zu seiner Pensionierung 1988 Chefarzt der Kinderheilstätte Aprath - später Klinik Aprath.

Herr Dr. Simon hat sich als Wissenschaftler durch seine hervorragenden Leistungen auf dem Gebiete der Pneumologie, die in unzähligen Vorträgen, in vielen Originalarbeiten und im Handbuch für Innere Medizin niedergelegt sind, hohes Ansehen erworben.

Der Sohn von Prof. Dr. med. Georg Simon, der 1910 die Kinderheilstätte Aprath gründete und wissenschaftlich durch die „tuberkulösen Lungenspitzenherde“ weltbekannt wurde, war von Kindheit an mit der Tuberkulose konfrontiert und so in die Fußstapfen seines Vaters getreten.

1970 habilitierte er sich für das Fach „Lungenkrankheiten“ und wurde 1973 Professor an der Universität Düsseldorf.

Im Heilstätten - später Klinikbereich begann von 1953 an ein Ausbau der Lungenchirurgie, Bronchoskopie und auch eines großen Lungenfunktionslabors für Kinder und Erwachsene. Durch die Weiterentwicklung neuer Antituberkulotika zeichnete sich sehr früh ein erheblicher Rückgang der Kindertuberkulose ab und so verstand es Herr Simon, sich früh den veränderten Ergebnissen anzupassen; es wurde aus einer Kinderheilstätte Aprath eine Klinik Aprath für sämtliche intra- und extrapulmonalen Tuberkulosen. In späteren Jahren wurde eine chirurgisch-orthopädische Abteilung gegründet. Unter vielen anderen Erkrankungen wurden nun eine Reihe von Paraplegien tuberkulöser Genese operiert und ausgeheilt.

1963 erhielt Herr Simon den Homburg-Preis der Universität Regensburg. Die Klinik Aprath wurde Lehrkrankenhaus der Universität Düsseldorf.

1977/78 war Herr Simon Präsident der Deutschen Gesellschaft für Lungenkrankheiten und Tuberkulose und richtete als deren Präsident den Deutschen Kongress für Lungenkrankheiten in Düsseldorf aus. Jahrelang war er Geschäftsführer der Rhein.-Westf. Vereinigung für Lungen- und Bronchialheilkunde.

Über viele Jahre war Prof. Simon engagiert für den Deutschen Paritätischen Wohlfahrtsverband tätig. In den siebziger Jahren wurde ihm das Bundesverdienstkreuz verliehen.

Auch heute noch hält Prof. Simon viele Vorträge und publiziert in medizinischen Zeitschriften. Entspannung findet er beim Golfspiel.

Zum 80. Geburtstag gratulieren wir ihm sehr herzlich.

Gerd Josef Hötter 